\title{
Human ignorance and education: a significant part of the global pollution crisis
}

\author{
J. T. Trevors
}

Published online: 1 December 2010

(C) Springer Science+Business Media, LLC 2010

The more uninformed the citizens of about 195 countries, the easier it is for politicians and so-called leaders to engage in activities that are disastrous for our singular, shared common biosphere. Nowhere is this more true than in the human ignorance concerning total global pollution of our biosphere. Currently, one could argue that the most significant form of global pollution is human population growth. However, in recent years, the debate has almost solely focused on greenhouse gas emissions and global warming. If one thinks that convincing 195 countries to agree upon a climate change accord is difficult, try envisioning about 195 countries agreeing to reduce human population growth through universal birth control. If the citizens of countries where democratic voting exists are ignorant of climate change, human population growth, the fundamental laws of thermodynamics and how it controls every aspect of human life, including the financial markets, poverty, hunger, food safety and security, and an agricultural production system that is at the mercy of local climates, global climate change and diseases, then it should not be too difficult to convince them of lower priority issues and obtain their votes in elections.

Ignorance is always the enemy, and it is often combined with fear, greed, corruption, agenda setting to serve special interest groups, discrimination, conflicts and other selfish agendas that often have little to do with the humanitarian needs of people. To alleviate this mass ignorance, the truly scholarly educational system is required. However, most

J. T. Trevors $(\bowtie)$

School of Environmental Sciences, University of Guelph,

Guelph, Ontario N1G 2W1, Canada

e-mail: jtrevors@uoguelph.ca educational systems are very much underfunded meaning they are controlled by political decisions not scholarly, academic decisions. What better way to ensure that forward, progressive, positive educational change for the good for all of humanity is slowed to a snail's pace. Today there are between 100 and 200 million children that are not even receiving an education. In many locations, the majority of these young children are female.

Citizens of the world need to understand subject matter in total global pollution, thermodynamics, human population growth, agricultural production and food distribution systems, potable water distribution systems, energy and communication networks and educational systems, as examples, in each of their countries. It is very likely that many humans have a poor understanding of how these activities are completely linked to each other. Again, ignorance is the problem and can only be combated with democratic constitutions, stable governments and scholarly educational systems that are funded at the level necessary to truly educate people for the future. Good things can only come from educational systems that deal with these priority topics and have students actively participating in recycling, reducing and reusing products, and educating students as to how the current generation will set the stage for future generations, especially human population numbers and global pollution.

In many unstable and failed countries even a basic education cannot be implemented. The number of students able to leave these countries and obtain an education in a developed country is a relatively small percentage. And in some cases, they do not return to their country of origin to work in the educational system. For example, the complete educational system in Haiti after the 2010 disaster must be completely reconstructed and how will several hundred thousand orphans be educated if the international 
community does not complete this task providing infrastructure, funding and teachers. Ignorance must be combated at the local, national and international levels so humans have a common shared future in a sustainable biosphere that is not polluted and overpopulated. Education is central to this in every country. 